\title{
М.Н. Долгих
}

\section{ТЕХНОЛОГИЯ ПРОЕКТИРОВАНИЯ ДЕКОРАТИВНЫХ ШРИФТОВ: ОТ ИДЕИ ДО РЕЗУЛЬТАТА}

\begin{abstract}
Статья посвящена раскрытию технологии проектирования декоративных шрифтов от идеи до результата, внедренной и апробированной автором статьи в рамках дисциплины "Проектирование шрифта», читаемой для графических дизайнеров на кафедре дизайна Томского государственного университета. Показана технология проектирования декоративных шрифтов с применением аналоговых и цифровых инструментов. Выявлено и обосновано, что творческий интерес у шрифтового дизайнера могут вызвать как фигуративные, так и абстрактные мотивы. Обозначаются возможные сферы применения освоенной технологии проектирования декоративных ииифтов.

Ключевые слова: декоративный шрифт, проектирование шрифта, графический дизайн, ирифтовой дизайн, экспериментальная типографика.
\end{abstract}

Актуальность исследования определяется двумя факторами, которые связаны с естественным желанием человека к расширению своих возможностей. С одной стороны, в современном обществе активно развивается сфера предпринимательства: очевиден количественный рост компаний-производителей товаров и услуг. В условиях конкуренции у предпринимателей появляется желание представлять не просто успешную, но выдающуюся среди аналогичных компанию. Увеличивается спрос на идентификацию, запоминающуюся уникальность бренда, и декоративный экспериментальный шрифт может стать одним из значимых элементов визуальных коммуникаций бренда. С другой стороны, в среде специалистов по визуальным коммуникациям, графических и шрифтовых дизайнеров существует интерес к творческому поиску новых выразительных средств в области шрифтовой графики. Шрифт является одним из базовых инструментов при построении визуальных коммуникаций в графическом дизайне. Если рассматривать шрифт с точки зрения его исторического развития, можно выявить, что он является отражением времени. В настоящее время большие возможности для дизайнеров открываются благодаря цифровым технологиям. Цифровая фотография, векторная, растровая, трехмерная графика могут комбинироваться с аналоговыми технологиями и позволяют проектировать разнообразные выразительные декоративные шрифты.

Шрифт - система условных знаков - букв, объединенных в алфавит, позволяющая с помощью графической записи фиксировать во времени и пространстве мысли человека. По мнению Эрика Шпикермана [1. С. 7], шрифт визуальный язык, который связывает автора сообщения с реципиентом.

В соответствии с назначением шрифты можно условно разделить на две группы: текстовые и акцидентные. В чем заключаются основные функциональные различия между текстовыми и акцидентными шрифтами? Текстовые шрифты предназначены для набора длинных информационных блоков, 
например, в книгах, журналах или газетах. Акцидентные шрифты предназначены для набора заголовков или небольших коротких фраз или выражений и используются для акциденции в публикациях или рекламе. Текстовые шрифты чаще всего работают в мелком кегле, в то время как декоративные акцидентные зачастую могут быть полноценно раскрыты лишь в крупном кегле. Информация, набранная текстовым шрифтом, ориентирована на длительное чтение, следовательно, одним из основных критериев качественного, профессионально сделанного текстового шрифта является удобочитаемость. Акцидентные шрифты предназначены для выделения, подчеркивания смысловых блоков в тексте и могут выходить за пределы чистых графем в сторону фигуративности, предметности, эмоциональности [2. С. 237].

Декоративные шрифты (как частный случай акцидентных шрифтов) легче переносят эксперименты в самом смелом смысле этого слова. Такие шрифты являются не просто средством передачи вербального сообщения, а воплощают в себе образное начало за счет линий, форм, цвета, текстур, становятся сильным визуальным сообщением, подчеркивающим смысл слова или фразы [3].

Во всем мире дизайнеры изучают, исследуют и расширяют пределы выразительных возможностей шрифтовой графики. Наиболее значимые разработки в области шрифта публикуются в книгах, участвуют в конкурсах и выставках, организуемых сообществом шрифтовых дизайнеров.

Международная организация Тайп Директорс Клаб [4], основанная в 1946 г. ведущими специалистами в области типографики и шрифтового дизайна в Нью-Йорке, ежегодно проводит конкурсы, по результатам которых лучшие работы участвуют в выставках по всему миру, а также размещаются в шрифтовом ежегоднике [5]. Мероприятия клуба - это презентация лучшего в сфере шрифтового дизайна и типографики за последний год. Здесь представлены выдающиеся примеры использования шрифта и типографики в дизайне плаката, видео- и веб-дизайне, а также в книжном, газетном и журнальном дизайне.

По мнению Стива Хеллера и Гейл Андерсон [6], слишком гладкий и вылизанный графический дизайн, распространенный в наши дни в связи с компьютеризацией, можно обогатить с использованием изысканных шрифтовых орнаментов. Книга «Новые орнаментальные шрифты: декоративные надписи в цифровом веке» представляет собой настоящий калейдоскоп высококлассных шрифтов, на создание которых дизайнеров вдохновляют природа, история и визуальное искусство. Среди направлений и стилей в культуре, визуальных мотивов и эффектов, годных для интерпретации в шрифтовом искусстве, в книге отражены викторианский стиль, хип-хоп, модерн, готика, текучесть, цветы, волосы, электричество и многое другое. Начиная с исторического обзора декоративных шрифтов и их эволюции с начала $\mathrm{XX}$ в. до наших дней, книга включает в себя сотни современных примеров шрифтовых работ со всего мира, организованных в три раздела: урок истории, природа и эклектика.

Книга «Шрифтовой дизайн: радикальные инновации и эксперименты», написанная Тил Тригс [7], руководителем аспирантуры на факультете искусства, дизайна и музыки в Кингстонском университете недалеко от Лондона, демонстрирует, насколько странными и грандиозными могут быть типогра- 
фические эксперименты. В книге опубликованы проекты 37 специалистов, признанных на международном уровне. Демонстрируется, что диапазон шрифтовых экспериментов может быть бесконечно разнообразным. Существует биоморфной шрифт, который изменяется в ответ на физиологическое состояние пользователя; арабский шрифт, который бросает вызов табу, связанным с кораническим текстом; шрифт, сделанный из оригами; шрифт, написанный с помощью спрея на тающем снегу, и множество других. Один из наиболее ценных уроков, который можно вынести из знакомства с книгой: шрифтовая графика - кирпичи и строительный раствор для практики графического дизайна, открывает дизайнерам значительную свободу для экспериментов. Т. Триггс утверждает, что экспериментирование - это не внешний вид, или стиль, или работа конкретного дизайнера, но это точка в процессе проектирования, когда границы условностей исчезают.

Русский графический и шрифтовой дизайнер Юрий Гулитов [8] специализируется на поиске эмоциональной выразительности кириллических шрифтовых форм через творческую каллиграфию и экспериментальную типографику. От шрифта дизайнер переходит к шрифтовому плакату, в котором выражает творческие идеи, представления о ритмах и пластике. Шрифты, которые Ю. Гулитов использует в плакатах, чаще всего являются авторскими, спроектированными, или рукописными, каллиграфическими. В своих работах профессиональный дизайн он комбинирует с самодельным графическим фольклором.

Компания эстонских дизайнеров Владимира Логинова и Максима Логинова «Хэндмэйдфонт» [9] специализируется на разработке уникальных нетрадиционных шрифтов. В качестве источников вдохновения дизайнеры используют все, что их окружает. Дизайнеры заинтересованы в запросах на разработку новых шрифтов для рекламных кампаний, упаковки, обложек журналов, различных решений визуальных коммуникаций для широкого круга клиентов и отраслей и считают, что хорошие идеи могут быть применены к чему угодно: от визитных карточек до наружной рекламы.

«36 дней шрифта» [10] - это проект, организованный Ниной Санс и Рафой Гоикоеча в Барселоне, который приглашает дизайнеров, иллюстраторов и художников-графиков со всего мира выразить свое неповторимое видение букв и цифр латинского алфавита. Проект предлагает 36 дней безостановочного творчества, когда участники ежедневно соревнуются в дизайне букв и цифр, в результате получая возможность посмотреть на одни и те же символы с разных точек зрения. Цель проекта - создать пространство для творчества в области шрифтовой графики и ее бесконечных выразительных возможностей.

Обзор информационных источников показывает, что в среде графических дизайнеров существует явный интерес к разработке разнообразных шрифтов и экспериментальной типографике. Декоративный шрифт можно проектировать для конкретной цели или дизайн-объекта. Также сферу проектирования декоративного шрифта можно использовать как площадку для игры с конструкциями, формами, образами, эмоциями. Проектная деятельность вообще есть неотъемлемая функция культуры и принадлежит к сфере духовно-практического [11]. Несмотря на значительную активность дизайнеров и явные достижения в области прикладных разработок декоративных шрифтов, 
в сфере теоретических исследований очевиден дефицит информации, раскрывающей технологические подходы к проектированию декоративных шрифтов.

Целью данного исследования является описание технологии проектирования декоративных шрифтов. Технология разработана автором статьи и апробирована в процессе обучения студентов 4-го курса по направлению «Графический дизайн» в рамках дисциплины «Проектирование шрифта»на кафедре дизайна Томского государственного университета.

Новизна статьи заключается в демонстрации пошаговой технологии проектирования декоративных шрифтов от идеи до результата. Данная технология доступна для освоения студентами художественных и дизайнерских вузов и факультетов, а также может быть полезна преподавателям шрифтовой культуры. Технологию могут применять и профессиональные практикующие графические дизайнеры, увлеченные экспериментальной типографикой.

Предложенная технология проектирования декоративных шрифтов нацелена на эффективность и результативность деятельности дизайнера и предполагает выполнение ряда последовательных этапов. На каждом этапе решаются определенные задачи.

На первом этапе осуществляется поиск идеи. Суть этого этапа заключается в творческой работе над формообразованием, т.е. образованием новых форм путем целенаправленной разнообразной компоновки заданных объектов. Заданными объектами являются буква и произвольная форма, элементы которых комбинируются и образуют логическую последовательность. На горизонтально ориентированном листе бумаги формата А4 в левой части нужно изобразить букву; рядом справа - случайную фигуру произвольной формы (фигура может быть абстрактной геометрической или предметной); далее заполнить строку фигурами, которые являются логическим продолжением данного ряда и объединяют в себе морфологические признаки графемы и случайной фигуры (рис. 1). Это проделывается для каждой буквы кириллического алфавита - всего 33 последовательности. Аналогичным образом можно проработать цифры и знаки препинания.

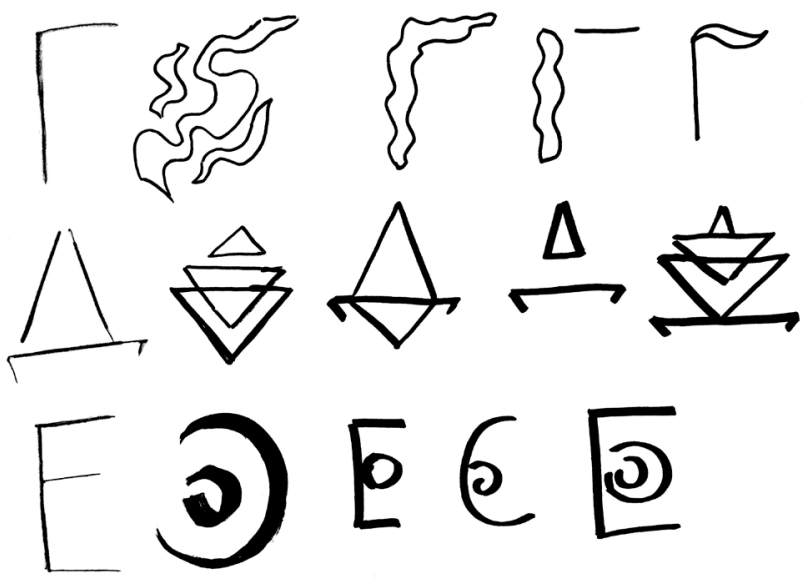

Рис. 1. Первый этап проектирования. Формообразование в декоративной шрифтовой графике. Автор: Вербицкая Дарья, гр. 1637, 2016 г. 
Второй этап заключается в анализе полученных результатов и отборе наиболее удачных последовательностей графем. Все выполненные работы выставляются на общий просмотр и обсуждаются студентами и преподавателем с учетом критериев отбора и аргументации высказанных мнений. Критериями отбора являются новизна, художественно-образная выразительность графем, а также потенциал для развития выбранных графем до уровня полноценного декоративного шрифта.

Третий этап - это рисование шрифта в эстетике выбранных на втором этапе графем с использованием в качестве основы их формообразующих элементов. Из 8-12 наиболее оригинальных последовательностей необходимо выбрать по одной графеме (всего 8-12 графем). Отбор происходит индивидуально в обсуждении преподавателя со студентом. Для каждой из отобранных графем в их же логике необходимо сконструировать остальные буквы алфавита. Ориентиром в выборе морфологических признаков, пластического решения остальных букв конкретного шрифта является фигура произвольной формы, которая лежит в основе отобранной графемы и служит формообразующим элементом (рис. 2). В результате этого этапа получается 8-12 принципиально разных шрифтов, которые можно считать качественными эскизами.

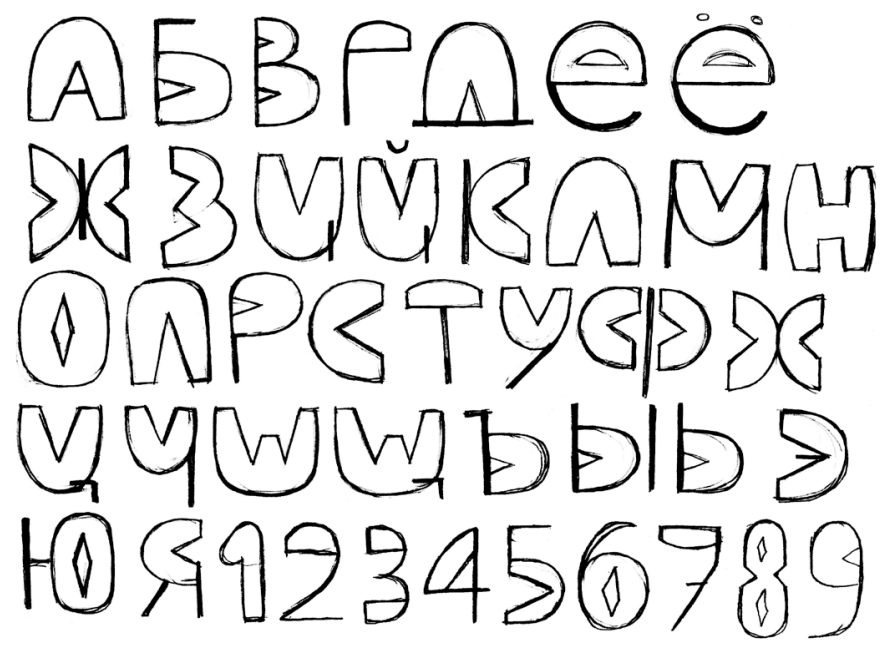

Рис. 2. Третий этап проектирования. Эскиз шрифта. Автор: Губанова Елизавета, гр. 1637, 2016 г.

На четвертом этапе происходит освоение различных подходов к доведению выбранных на третьем этапе эскизов до результата. Задача - сделать четыре готовых шрифта, каждый из которых выполняется в одной из предложенных техник: 1) уникальная графика, 2) растровая графика или фотографика, 3) векторная графика, 4) трехмерная графика. Из 8-12 шрифтовых эскизов студент в обсуждении с преподавателем выбирает 4 наиболее выразительных. При выборе необходимо учитывать логику сочетания инструмента и формы, взаимосвязь между пластическим решением шрифта и предполагаемой техникой исполнения.

Рассмотрим возможности предложенных техник для проектирования декоративных шрифтов. Уникальная графика позволяет передать эстетику аналоговых инструментов, живые линии, энергию рукотворных образов. Шрифт 
в уникальной графике создается с помощью таких инструментов и материалов, как карандаши, уголь, мел, ручки, фломастеры, маркеры, перья и тушь, кисти и краски и т.д. Для нанесения можно использовать бумагу, пластик, стекло, металл, дерево или любые другие поверхности, пригодные для рисования. Уникальная графика открывают широкий диапазон возможностей для экспериментов; в результате получаются уникальные декоративные шрифты. Шрифт «Маслоу» выполнен масляной пастелью (рис. 3), шрифт «Распыление» изготовлен с помощью трафаретов и распыляющего краску баллончика (рис. 4), шрифт «Мел и доска» нарисован мелом на поверхности доски (рис. 5).
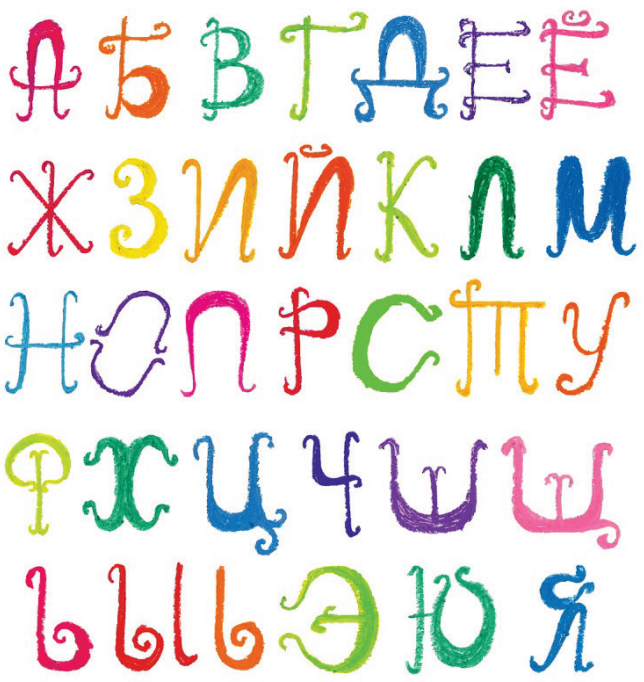

Рис. 3. Шрифт «Маслоу», уникальная графика. Автор: Иванова Дарья, гр. 1627, 2015 г.

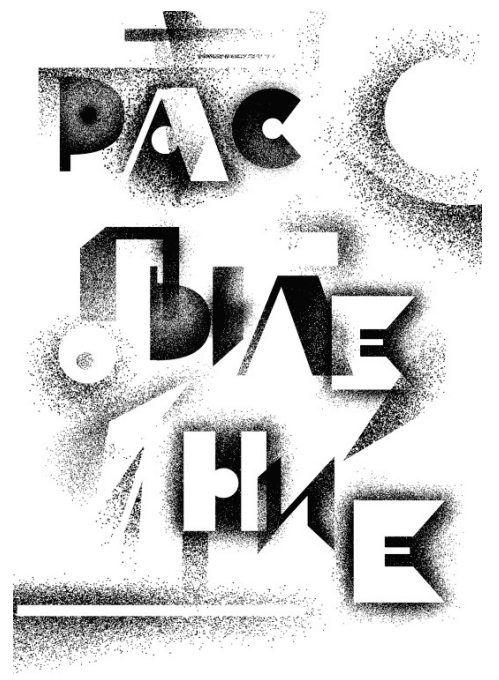

Рис. 4. Шрифт «Распыление», уникальная графика. Автор: Грезина Маргарита, гр. 1637, 2016 г.

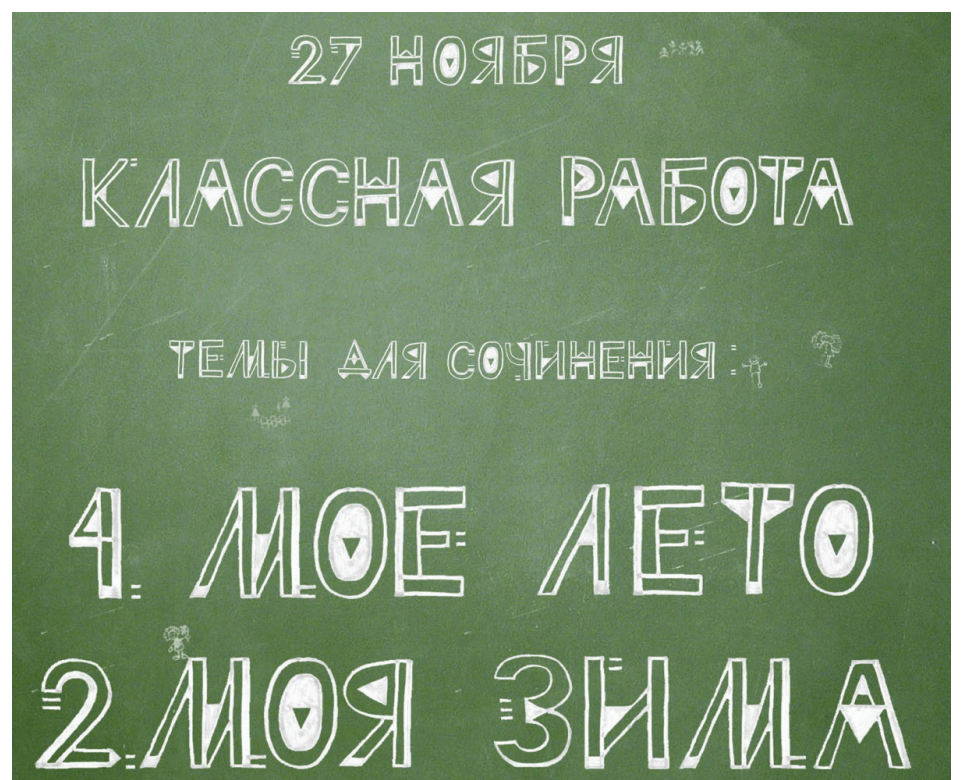

Рис. 5. Шрифт «Мел и доска». Автор: Матецкая Марина, гр. 1617, 2014 г. 
Растровая графика и цифровая фотографика позволяют воплощать фотореалистические образы, сложные богатые цветотональные решения, представленные в виде растра, т.е. графической матрицы. Фотошрифт - это шрифт, который формируется из предметов или явлений окружающего пространства, снятых на камеру; предполагает наличие у дизайнера навыков создания постановочной фотографии и работы с освещением, а также умения обрабатывать полученные изображения в редакторе растровой графики Adobe Photoshop. Декоративный фотошрифт может быть воплощен в самых разнообразных эмоциональных образах. Шрифт «Пекло» представляет собой буквы в виде угольков местами горящих, местами тлеющих, а местами рассыпающихся в пепел (рис. 6). Графемы в шрифте «Морской» причудливой формы, составлены из морских раковин и навевают мысли о спокойствии и умиротворении (рис. 7). Шрифт «Герберы» яркий, сочный, растительный, скомпонован из цветов и листьев (рис. 8).

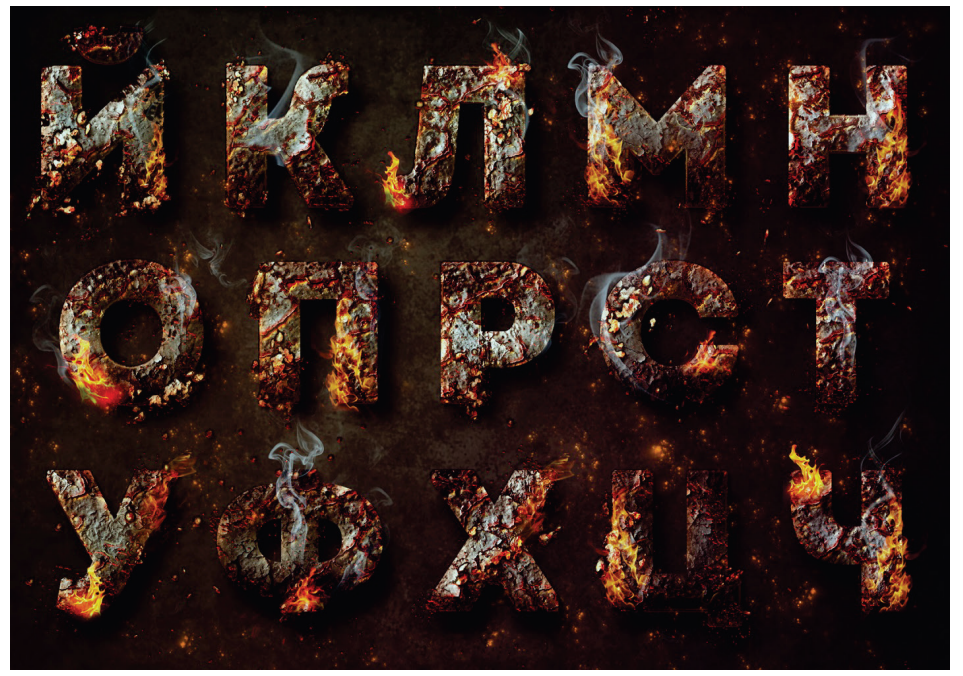

Рис. 6. Фрагмент шрифта «Пекло», растровая графика. Автор: Африка Алиса, гр. 1627, 2015 г.

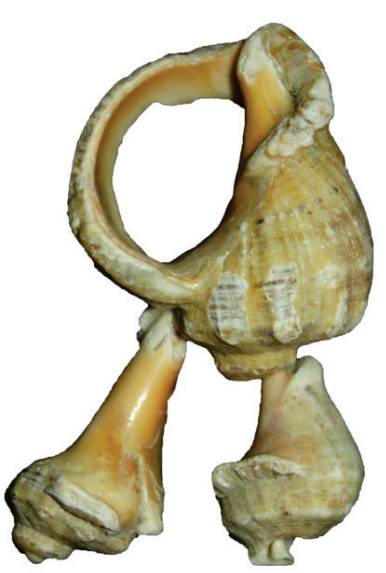

Рис. 7. Графема «Я» из фотошрифта «Морской». Автор: Львова Диана, гр. 1697, 2012 г.

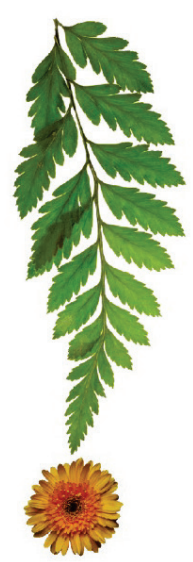

Рис. 8. Восклицательный знак из фотошрифта «Герберы». Автор: Рыкова Светлана, гр. 1637, 2016 г. 
Векторная графика основана на математическом описании элементарных геометрических объектов (примитивов): точек, линий, фигур; позволяет параметрически настраивать объекты и при масштабировании сохранять высокое качество изображения. Путем комбинирования примитивы образуют более сложные конструкции и формы. Векторный декоративный шрифт можно построить, следуя эскизу, в графическом редакторе Adobe Illustrator или CorelDraw. Художественно-образная выразительность декоративного векторного шрифта может быть усилена за счет применения к графемам или элементам графем различных эффектов, заполнения их цветом, градиентом или текстурой.

Рассмотрим примеры векторных декоративных шрифтов. Каждая графема в шрифте «Геометрия» - композиция из планиметрических фигур, т.е. фигур, которые располагаются в пределах одной плоскости: треугольников, прямоугольников, окружностей; преобладающим средством выразительности являются линии, и в небольшом количестве распределены цветовые пятна (рис. 9). Шрифт «Третья планета от Солнца» состоит из моноширинных линий и окружностей разного диаметра (рис. 10). Шрифт «Кноп» основан на образе цилиндрической кнопки, меняющей от графемы к графеме окрас, угол поворота риски и положение выступающих плоскостей (рис. 11).

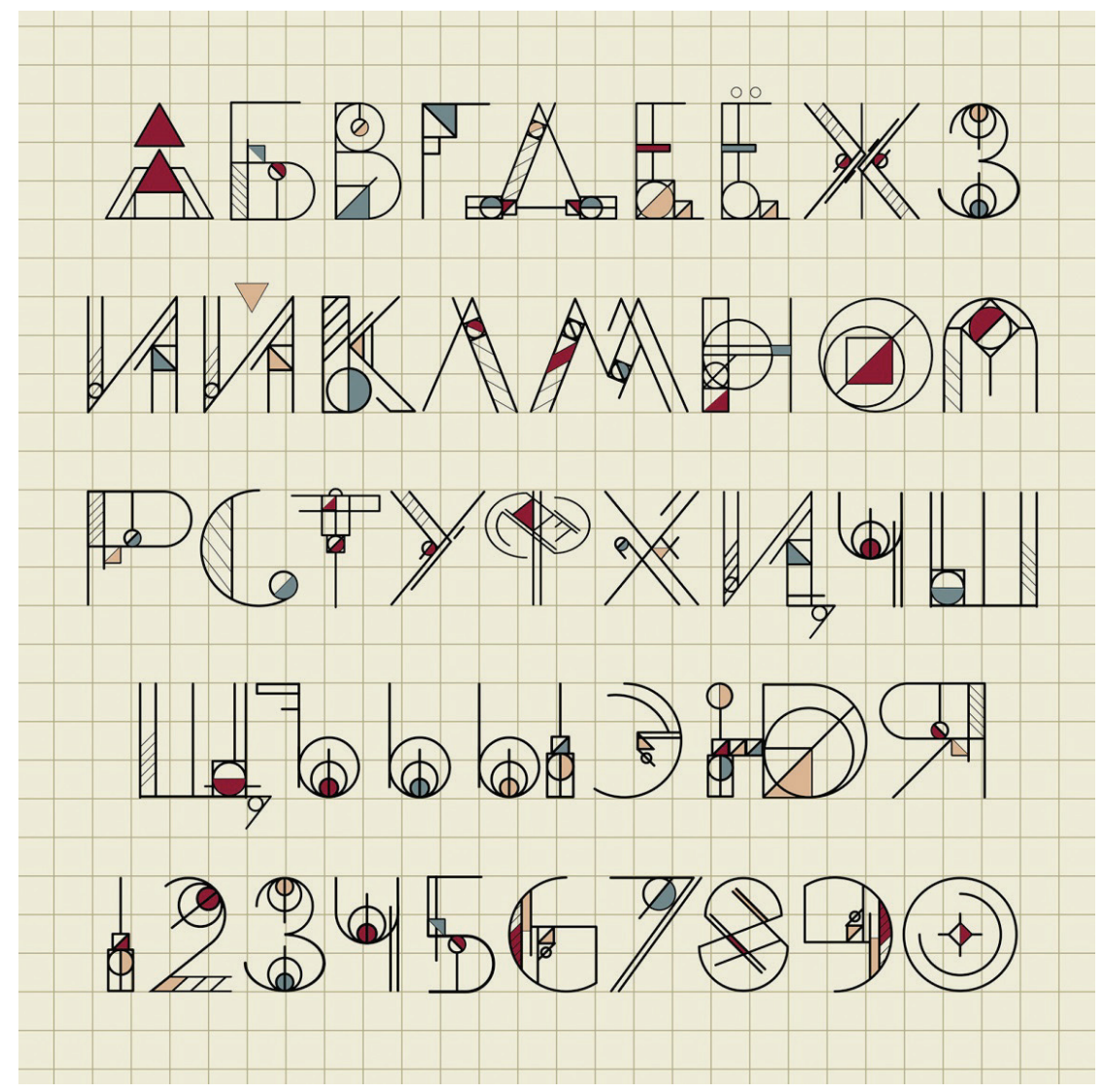

Рис. 9. Векторный шрифт «Геометрия». Автор: Егорова Валерия, гр. 1627, 2015 г. 


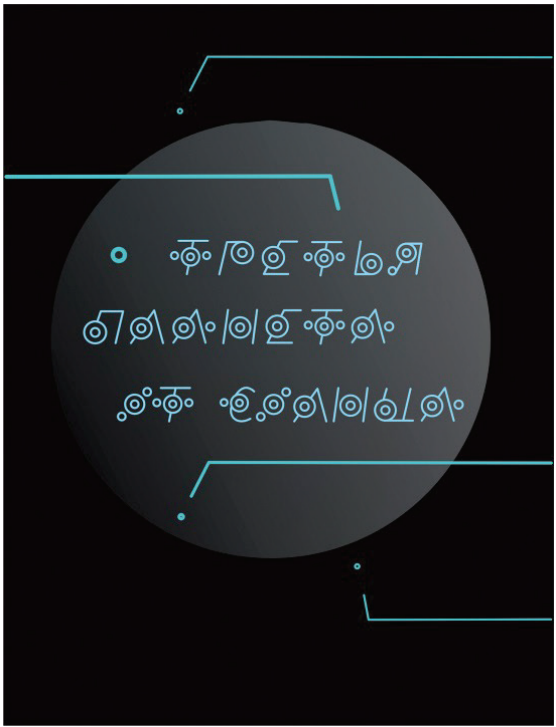

Рис. 10. Векторный шрифт «Третья планета от Солнца». Автор: Бурьян Алена, гр. 1697, 2012 г.
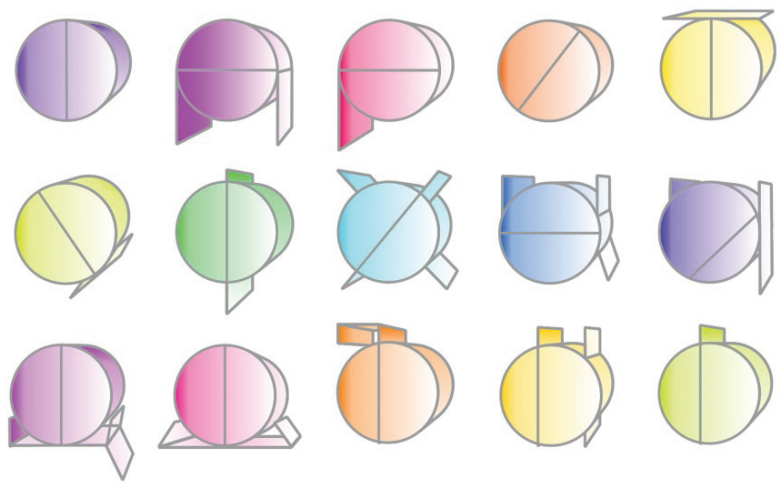

Рис. 11. Векторный шрифт «Кноп». Автор: Горковенко Ксения, гр. 1697, 2012 г.

Трехмерная графика позволяет создавать виртуальные объемные модели, которые можно рассматривать с разных сторон, в разных ракурсах, в условиях различного освещения в трехмерном пространстве. Смоделировать можно твердые поверхности, легко поддающиеся математическому описанию (архитектура, транспорт, объекты мебели). Объекты живой природы, которые содержат уникальные решения поверхности, удобно воплощать с помощью скульптинга (растения, животные, человек). Физические взаимодействия, например столкновения объектов или состояния материи: вода, пар, огонь и т.д. - можно симулировать посредством различных алгоритмов. Альтернативным способом получения трехмерных конструкций является комбинирование готовых трехмерных объектов из библиотек.

После того как готова объемная форма или конструкция, ее можно окрасить или затекстурировать. Затем установить и настроить источники освещения и визуализировать, т.е. построить проекцию в соответствии с выбранной физической моделью. Далее следует композитинг - доработка изображения. 
Трехмерный шрифт создается в таких редакторах, как 3ds Max и Z-brush. Трехмерный шрифт проектируется в виртуальном трёхмерном пространстве, которое отображается на плоской двумерной поверхности дисплея или листа бумаги. Кроме того, графемы могут быть материализованы посредством 3D-печати.

Графемы в шрифте «Цепи» образуются из переплетения голубых и розовых кольцеобразных звеньев (рис. 12). Шрифт «Планета» воплощает фантастическую идею о том, что в космосе есть планеты в виде графем, которые основаны на взаимодействии различных торов, по цвету напоминающих поверхность Земли (рис. 13). В шрифте «Мондриан» дихотомии вертикаль горизонталь, цвет - нецвет, большая поверхность - малая поверхность образуют в трехмерном пространстве структуру графем; цветовая палитра формируется из открытых основных цветов: желтого, красного, синего, белого и черного (рис. 14).

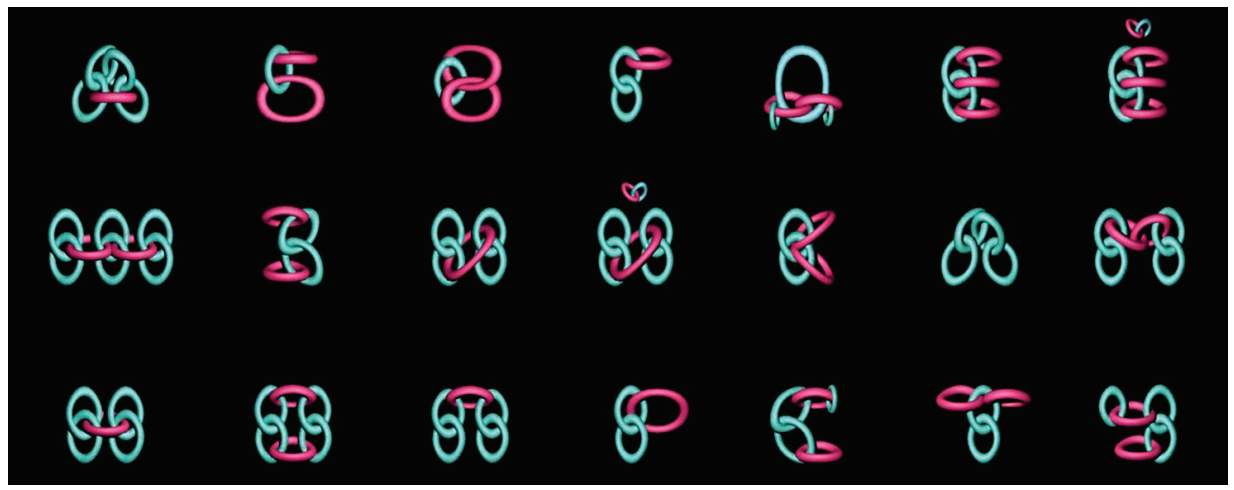

Рис. 12. Трехмерный шрифт «Цепи». Автор: Прушинская Екатерина, гр. 1687, 2011 г.

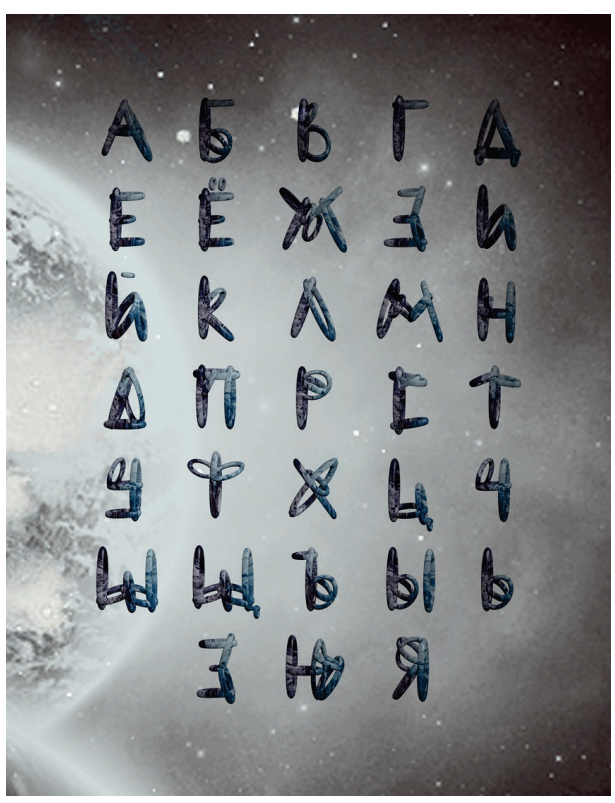

Рис. 13. Трехмерный шрифт «Планета». Автор: Емельянова Юлия, гр. 1697, 2012 г.

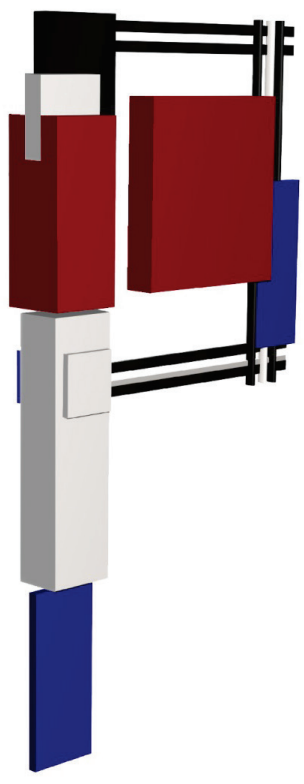

Рис. 14. Буква «Р» из трехмерного шрифта «Мондриан». Автор: Терентьева Дарья, гр. 1627, 2015 г. 
Заключительный, пятый, этап - поиск названия, тематического диапазона и области применения. При проектировании шрифта непременно нужно ответить на вопрос, где данный шрифт будет использоваться [12. С. 64]. Поиск названия осуществляется исходя из эмоционально-образной выразительности шрифта. Далее подбираются слова и фразы, раскрывающие тематический диапазон названия. Слова и фразы составляются в шрифтовые композиции перемещением букв как объектов вручную. Шрифтовые композиции демонстрируют возможную область применения шрифта. Смысловая выразительность слов или фраз в шрифтовом плакате достигается образностью шрифта, ритмическим строем и целостностью шрифтовой композиции. Рисунок декоративного шрифта передает определенное настроение: пафос или романтику, призыв к действию или спокойное напоминание, драматизм или сатиру, юмор или другие ассоциации [13].

Тематический диапазон декоративных шрифтов может быть сколь угодно разнообразным и в значимой мере задается формообразующим элементом. Характер формообразующего элемента, фигуративный или абстрактный, влияет на образ шрифта.

Окружающее пространство: как мир природы, так и мир культуры - богато идеями. Среди примерных направлений поиска идей при проектировании декоративных шрифтов можно выделить следующие: люди, животные, растения, насекомые, подводный мир, космос, архитектурные постройки, материалы (дерево, камень), свойства материалов (текучесть, гибкость), большие стили в искусстве (готика, викторианский стиль, модерн), музыка (джаз, классика), мода, кино, еда, творчество, цифровые технологии, абстрактные мотивы и т.д.

Важно обратить внимание на то, что объекты графического дизайна немыслимы без шрифта. Дизайн рекламного плаката или театральной афиши, книги или журнала, этикетки или упаковки предполагает наличие шрифтовой надписи, которая в свою очередь советует или предлагает, разъясняет или предупреждает, указывает или призывает. В зависимости от смысла сообщения надпись может быть активная, броская, спокойная, малозаметная и др., и дизайнер подбирает наиболее подходящий шрифт: строгий или свободный, контурный или объемный, легко читаемый или декоративный [14].

Декоративность шрифта, с одной стороны, противоречит его основному назначению: она усложняет графику букв и следовательно затрудняет удобочитаемость. С другой стороны, декоративная стилизация, усложнение формы основных и соединительных штрихов, засечек, выносных элементов, своеобразная ритмическая и пластическая организация букв, слов или надписей придают шрифтовым композициям неповторимую характерность [15].

Подводя итоги, следует заметить, что компетенции, полученные в рамках освоения предложенной в данной статье технологии проектирования декоративных шрифтов, важны в профессиональной деятельности графического дизайнера. Декоративные шрифты, спроектированные по технологии, можно применять для акциденции в самых разнообразных направлениях графического дизайна: в логотипах, брендинге, рекламе, плакатах, упаковке, макетах журналов и книг, веб-сайтах и т.д.

В заключение остается добавить, что невероятная свобода доступа к шрифтам любых стилей и эпох поставила дизайнера перед проблемой эсте- 
тики выбора [16]. Технология проектирования декоративных шрифтов, основанная на соединении случайного и закономерного, рационального и иррационального актуализирует в шрифтах и типографике ультрамодные контрасты рандомных предпочтений и эклектики, что вполне соответствует окружающей реальности, духу времени.

\section{Литература}

1. Шиикерман Э. О шрифте. М. : Паратайп, 2005. 192 с.

2. Кудрявиев А.И. Шрифт: история, теория, практика. М.: Изд-во ун-та Натальи Нестеровой, 2003. 248 с.

3. Таранов Н.Н. Художественно-образная выразительность шрифтов. Волгоград : Перемена, 2000. $168 \mathrm{c}$.

4. The Type Directors Club [Electronic resource] // Promoting excellence in typography for over 70 years. Electronic data. New York, 2017. URL: https://www.tdc.org (access date: 16.03.2017).

5. Typography 27: the Annual of the Type Directors Club. New York : Harper Collins Publishers, 2006. $340 \mathrm{p}$.

6. Heller S., Anderson G. New ornamental type: decorative lettering in the digital age. New York: Thames \& Hudson, 2010. 192 p.

7. Hall P. Type design: Radical innovations and experimentation // Print. 2004. № 58 (1). P. 34-35.

8. Серов С. И. Юрий Гулитов // Звезды графического дизайна. M. : Alma Mater, 2007. 132 с.

9. Handmadefont [Electronic resource]. Electronic data. Estonia, 2008-2017. URL: http://handmadefont.com/ (access date: 16.03.2017).

10. 36daysoftype [Electronic resource] / A project that aims to be a space for creation around typography and its endless graphic possibilities. Electronic data. [S. 1.], 2017. URL: http://www.36daysoftype.com (access date: 16.03.2017).

11. Балабанов П.И., Миненко Г.Н. Проектность культуры: теоретический и методологический аспекты. Кемерово : Кузбассвузиздат, 2002. 262 с.

12. Гордон Ю. Книга про буквы от Аа до Яя. М. : Изд-во студии Артемия Лебедева, 2006. $384 \mathrm{c}$.

13. Смирнов С.И. Шрифт и шрифтовой плакат. М. : Плакат, 1977. 144 с.

14. Декоративные шрифты: для художественно-оформительских работ / сост. Г.Ф. Кликушин. Минск : Полымя, 1987. 287 с.

15. Белов С.А., Чуйко Л.В. Декоративный шрифт // Омский научный вестник. 2013. № 4 (121). C. 203-206.

16. Барышников Г.М. Шрифты. Разработка и использование. М. : ЭКОМ, 1997. 288 с.

Dolgikh Maria N. National Research Tomsk State University (Tomsk, Russian Federation). E-mail: m.dolgich@gmail.com

Tomsk State University Journal of Cultural Studies and Art History, 2018, 30, pp. 43-55.

DOI: $10.17223 / 2220836 / 30 / 5$

TECHNOLOGY OF DECORATIVE FONT DESIGN: FROM IDEA TO RESULT

Keywords: decorative font; font design; graphic design; type design; experimental typography.

The relevance of the research is determined by two factors. On one hand, the sphere of entrepreneurship is developing, with the quantitative growth of companies producing goods and services, and competition is increasing. In this regard, the demand for identifying, the memorable uniqueness of a brand is increasing, and the decorative experimental font can become one of the significant elements of the brand's visual communication. On the other hand, among specialists in visual communications and graphic and font designers, there is an interest in the creative search for new expressive tools in the field of font graphics.

Font is one of the basic tools for building visual communications in graphic design. If we consider the typeface in terms of its historical development, it is possible to identify that it is a reflection of the time. At present, great opportunities for designers have been opened up by digital technologies. Digital photography, vector, raster, and three-dimensional graphics can be combined with analog technologies and allow you to design a variety of expressive decorative fonts. All over the world, designers study, explore, and expand the limits of the expressive possibilities of font graphics. The most signifi- 
cant developments in the field of font are published in books and are displayed in contests and exhibitions organized by the community of font designers.

The problem is that, despite the considerable activity of designers and obvious achievements in the field of applied decorative fonts, there is a lack of information in the field of theoretical research showing the technological approaches to the design of decorative fonts.

The purpose of this study is to describe technology for designing decorative fonts. The technology was developed by the author of the article and tested in the process of teaching the 4th year students in the area of "Graphic Design" in the discipline "Designing a font" at the Design Department of Tomsk State University.

The novelty of this article is the demonstration of a step-by-step method for designing decorative fonts: from idea to result. This technology is available for mastering by students of art and design universities and faculties, and can also be useful for teachers of font culture. The technology can also be applied by practicing professional graphic designers who are enthused by experimental typography.

The practical significance of this method is that the proposed technology for designing decorative fonts is aimed at the efficiency and effectiveness of the designer's activities and involves the implementation of a number of consecutive stages. At each stage, certain tasks are comleted.

The theoretical significance of it lies in the fact that expressive possibilities of graphics (unique, raster, vector and three-dimensional) are analyzed on specific examples when forming the emotional image of a decorative font. It has been demonstrated that both the figurative and the abstract motifs can arouse a font designer's creative interest. A list of exemplary directions for searching for ideas when designing decorative fonts is proposed. The possible areas of application of the technology for designing decorative fonts are indicated.

\section{References}

1. Shpikerman, E. (2005) O shrifte [On the font]. Moscow: Paratayp.

2. Kudryavtsev, A.I. (2003) Shrift: istoriya, teoriya, praktika [Fonts: history, theory, practice]. Moscow: Natalia Nesterova University.

3. Taranov, N.N. (2000) Khudozhestvenno-obraznaya vyrazitel'nost' shriftov [Artistic expressiveness of fonts]. Volgograd: Peremena.

4. The Type Directors Club. (n.d.) [Online] Available from: https://www.tdc.org. (Accessed: 16th March 2017).

5. Anon. (2006) Typography 27: the Annual of the Type Directors Club. New York: Harper Collins.

6. Heller, S. \& Anderson, G. (2010) New Ornamental Type: Decorative Lettering in the Digital Age. New York: Thames \& Hudson.

7. Hall, P. (2004) Type design: Radical innovations and experimentation. Print. 58(1). pp. 34-35.

8. Serov, S.I. (2007) Yuriy Gulitov [Yuri Gulitov]. In: Anikst, M. \& Serov, S.I. Zvezdy graficheskogo dizayna [The Stars of Graphic Design]. Moscow: Alma Mater.

9. Handmadefont.com. (n.d.) A Unique Collection of Handmade, 3D, Animated Fonts and Graphics from Handmadefont Studio and the best Designers from Around the World. [Online] Available from: http://handmadefont.com/. (Accessed: 16th March 2017).

10. 36daysoftype.com. (n.d.) A project that aims to be a space for creation around typography and its endless graphic possibilities. [Online] Available from: http://www.36daysoftype.com. (Accessed: 16th March 2017).

11. Balabanov, P.I. \& Minenko, G.N. (2002) Proyektnost' kul'tury: teoreticheskiy i metodologicheskiy aspekty [Projectivity of culture: theoretical and methodological aspects]. Kemerovo: Kuzbassvuzizdat.

12. Gordon, Yu. (2006) Kniga pro bukvy ot Aa do Yaya [A Book about the Letters from Aa to Yaya]. Moscow: Studiya Artemiya Lebedeva.

13. Smirnov, S.I. (1977) Shrift i shriftovoy plakat [Font and Font Placard]. Moscow: Plakat.

14. Klikushin, G.F. (ed.) (1987) Dekorativnyye shrifty: dlya khudozhestvenno-oformitel'skikh rabot [Decorative fonts: for artistic design works]. Minsk: Polymya.

15. Belov, S.A. \& Chuyko, L.V. (2013) Dekorativnyy shrift [Decorative fonts]. Omskiy nauchnyy vestnik-Omsk Scientific Bulletin. 4(121). pp. 203-206.

16. Baryshnikov, G.M. (1997) Shrifty. Razrabotka i ispol'zovaniye [Fonts. Development and Use]. Moscow: EKOM. 